\title{
Trash or Treasure? Considerations for Future Ecological Research to Inform Oil and Gas Decommissioning
}

\author{
Marie-Lise Schläppy ${ }^{1,2,3 *}$, Lucy M. Robinson ${ }^{1,2,4}$, Victoria Camilieri-Asch ${ }^{1,5}$ and \\ Karen Miller ${ }^{2}$ \\ ${ }^{1}$ Oceans Graduate School, The University of Western Australia, Perth, WA, Australia, ${ }^{2}$ Oceans Institute, The University of \\ Western Australia, Perth, WA, Australia, ${ }^{3}$ Australian Institute of Marine Science, Perth, WA, Australia, ${ }^{4}$ CSIRO Oceans and \\ Atmosphere, Hobart, TAS, Australia, ${ }^{5}$ Centre for Transformative Biomimetics in Bioengineering, School of Mechanical, \\ Medical and Process Engineering, Faculty of Engineering, Queensland University of Technology, Brisbane, QLD, Australia
}

Numerous oil and gas (O\&G) installations worldwide will need to be decommissioned in the near future. Complete removal of subsea structures is often the default approach although some regions retain structures under rigs-to-reefs programs. Here, we reviewed the published literature to understand the status of global research on decommissioning, and specifically identify gaps in ecological knowledge. We estimated the frequency of different research categories (i.e., themes, and spatial/temporal scales), and tested the assumption that the number of papers across the categories of each research aspect was even in distribution. However, the frequency of studies focusing on biodiversity at a local $\left(\leq 100 \mathrm{~km}^{2}\right)$ scale (relative to regional and oceanic and pan-oceanic scales) were significantly higher; while other theme categories (e.g., ecotoxicology, connectivity, structural-integrity, restoration and other) were significantly lower than expected. Temporally, $\leq 1$-year studies were more frequent than multiyear studies, but these frequencies did not significantly deviate from the assumed distribution of equal frequencies. We propose that further research be carried out to evaluate the benefits of both retention and removal of structures. Ecological research on decommissioning should extend its focus beyond biodiversity, to include eco-toxicology, structural-integrity, connectivity at larger spatial and temporal scales. This would provide a more holistic assessment of ecological impacts to inform sustainable and equitable development choices in multiple Blue Economy sectors, as we transition from offshore O\&G to marine renewables.

Keywords: subsea structures, decommissioning, offshore wind, marine renewables, rigs-to-reefs, oil and gas (O\&G) industry, offshore \& marine structures

\section{DECOMMISSIONING OF OIL AND GAS SUBSEA STRUCTURES: A GROWING ISSUE}

Worldwide, oil and gas $(\mathrm{O} \& \mathrm{G})$ companies are facing the challenge of managing unproductive subsea infrastructure that cannot be re-purposed (Cullinane and Gourvenec, 2017). Retiring infrastructure and returning a title to regulators is known as decommissioning. This process can encompass anything from complete removal to leaving subsea structures in place (in situ decommissioning), with numerous options in between (Techera and Chandler, 2015; Fam et al., 2018; Sommer et al., 2019). Full removal is the default regulatory position in the United Kingdom and in Australia. In the North Sea, the OSPAR convention specifies that a derogation could be 
obtained for steel foundations weighing over 10,000 t (OSPAR, 1998). Australia has a mechanism to assess decommissioning on a case-by-case basis, where the risk needs to be "as low as reasonably possible" (ALARP) (NOPSEMA, 2020). In the United States, policies vary from full removal to decommissioning in situ (Kaiser and Pulsipher, 2005). The Gulf of Mexico's is often cited for its rigs-to-reef program (Fam et al., 2018). However, policies are set to evolve based on experience in given countries, and shared knowledge worldwide.

There are several presumed drivers for leaving retired subsea structures in situ. These include cost savings, logistics, including avoiding potentially unsafe operations at sea, and creating artificial reefs. In addition to ecological considerations, the social (including public perception) and economic dimensions are an important part of multi-criteria assessments and approaches, that consider these varied criteria (e.g., Fowler et al., 2014). Net environmental benefits analysis offers a way to compare and rank net environmental benefits associated with management alternatives and can be used in assessing decommissioning options but research on its merit for in situ decommissioning is needed. Stakeholders have concerns regarding the social, economic, and environmental aspects of decommissioning and a comprehensive list of questions on the risks and benefits are given in Shaw et al., 2018. In this article, we focus solely on research questions and research pertaining to the potential ecological value of biological assemblages on and around $\mathrm{O} \& \mathrm{G}$ infrastructure. This is generating considerable interest among regulators, industry, and scientific communities, who seek to understand the environmental implications of in situ decommissioning.

As decommissioning is of increasing international relevance (International Energy Agency, 2019), it is important to review existing research and identify gaps in knowledge, to direct future research and facilitate evidence-based decisions by policy makers. To this effect, we evaluated the peer-reviewed ecological research on in situ decommissioning and assessed research questions formulated by experts (Fowler et al., 2019) and stakeholders (Shaw et al., 2018). While we recognize that decisions regarding decommissioning will necessarily be multifaceted and include engineering, social, economic considerations, as well as environmental ones, we focus here specifically on environmental inputs to decommissioning decisions. This review highlights where future research efforts can be targeted to gain a more holistic view of in situ decommissioning of subsea O\&G infrastructure, and thus better inform government policy and industry decisions worldwide.

\section{ANALYZING GLOBAL ECOLOGICAL RESEARCH ON DECOMMISSIONING THROUGH PUBLISHED RESEARCH AND RESEARCH QUESTIONS}

We found global research articles on in situ decommissioning through an electronic search using Web of Science and Google Scholar. We used several combinations of the following keywords to search both databases: "decommissioning," “offshore," “infrastructure," “platform," “pipeline," “oil," “gas," "rigs-to-reefs," “subsea," “marine," “environment," “ecosystem," "future," and "impact."

The literature search was limited to terms that related directly to decommissioning. This gave results that regulators are likely to find when carrying out a similar search. In total, the literature searches yielded 182 records pertaining to ecological aspects of decommissioning (Supplementary Material). Those records came predominantly from North America (35.2\%), Europe (26.4\%), and Australia (9.9\%), and 61.5\% were published in the last 5 years. Few contributions came from the Middle East (0.5\%), Africa (1.1\%), South America (3.3\%) and Asia (3.8\%). Peerreviewed publications accounted for 59.3\% (108) of the search results and the rest was "gray literature," composed of conference contributions, seminars, workshops $(11 \%)$, reports $(8.8 \%)$, theses (3.8\%), and other (17\%) (Supplementary Material). In the peer-reviewed literature, $44.4 \%$ were studies with primary data obtained through biological/ecological field work, experiments and/or modeling; while the remaining were papers on methods (4.6\%), frameworks (5.6\%), concepts (29.6\%), and other $(15.7 \%)$.

Ecological research on decommissioning of $\mathrm{O} \& \mathrm{G}$ infrastructure was analyzed by identifying the (1) main theme, (2) temporal scale, and (3) spatial scale specific to each paper. This was carried out via content analysis (Krippendorff, 2004) and chi-squared goodness-of-fit tests. Content analysis was used to identify the frequency of research themes as well as the spatial and temporal scale of studies. Each paper was classified into one of five common research themes, stemming from the research questions developed by experts (Fowler et al., 2019) and stakeholders (Shaw et al., 2018). Publications were assigned to one theme only, as their focus fell clearly in one category. The research themes were: biodiversity, connectivity, ecotoxicology, structural integrity (i.e., how a collapsing or crumbling structure affects the biological assemblages on and around it), restoration (of historical assemblages at the site that were present prior to the structure being commissioned) and "other." The literature was classified into two temporal scales of data collection - i.e., $\leq 1$ year or multi-year - and four spatial scales of data collection - i.e., local $\left(\leq 100 \mathrm{~km}^{2}\right)$, regional $\left(1,000 \mathrm{~km}^{2}\right)$, ocean and pan-ocean.

We tested the assumption that studies in research themes, spatial and temporal scales categories would occur with an equal probability using chi-squared goodness-of-fit tests. Statistical analyses were conducted in the $\mathrm{R}$ language for statistical computing ( $\mathrm{R}$ Core Team, 2021). The observed frequencies of each of these research categories were tested independently, but we represented the frequency of interactions between theme, spatial and temporal scale categories using a mosaic plot with the “ggplot2" package in R (Wickham, 2016).

Biodiversity was the focus of $91.7 \%$ of all peer-reviewed studies with primary data and the main research question (60.3\%) (Figure 1). Thirteen of the 44 biodiversity studies used video footage derived from routine engineering inspections with remotely operated vehicles (ROVs), rather than footage from specially designed scientific field campaigns. Of the biodiversity studies, $43.2 \%$ were on fish and other species of commercial interest. The presence of such species on structures was typically 


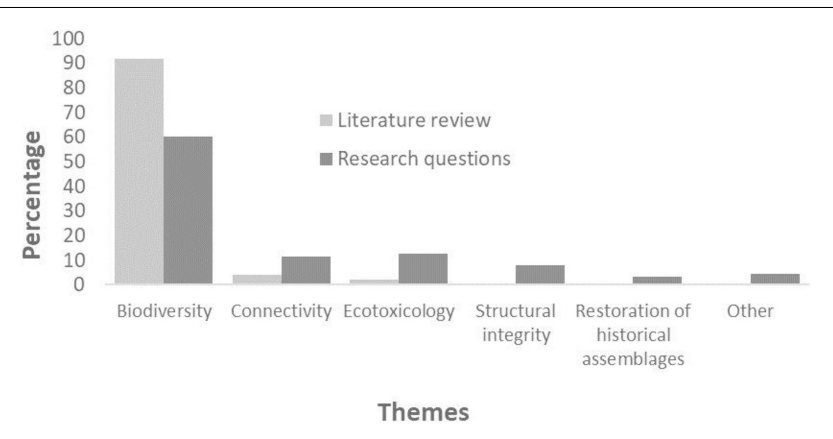

FIGURE 1 | Prevalence of common ecological research themes in global peer-reviewed publications and priority research questions formulated by experts (Fowler et al., 2019) and Australian stakeholders (Shaw et al., 2018).

used to demonstrate the ecological value of the infrastructure as a habitat, in that it increases local biodiversity. Another cited value of infrastructure was its presumed protective role against trawling and a negative value was its possible role in spreading marine invasive species (Fowler et al., 2018, 2019). Only 9.1\% of biodiversity studies were focused on non-native or invasive species, the presence of which was typically used to support removal of subsea infrastructure. Published research was most frequently conducted at a local scale (i.e., $\leq 100 \mathrm{~km}^{2} ; 98 \%$ ), and over short periods of time ( $\leq 1$ year) (Figure 2 ).

We found that developed nations that have started the decommissioning process (United States, United Kingdom, Australia) produce more peer-reviewed publications than other regions of the world, such as Asia, where decommissioning has also begun. We also found that the literature is dominated by studies on biodiversity (mostly fish species of commercial value) rather than being spread across themes selected by stakeholders

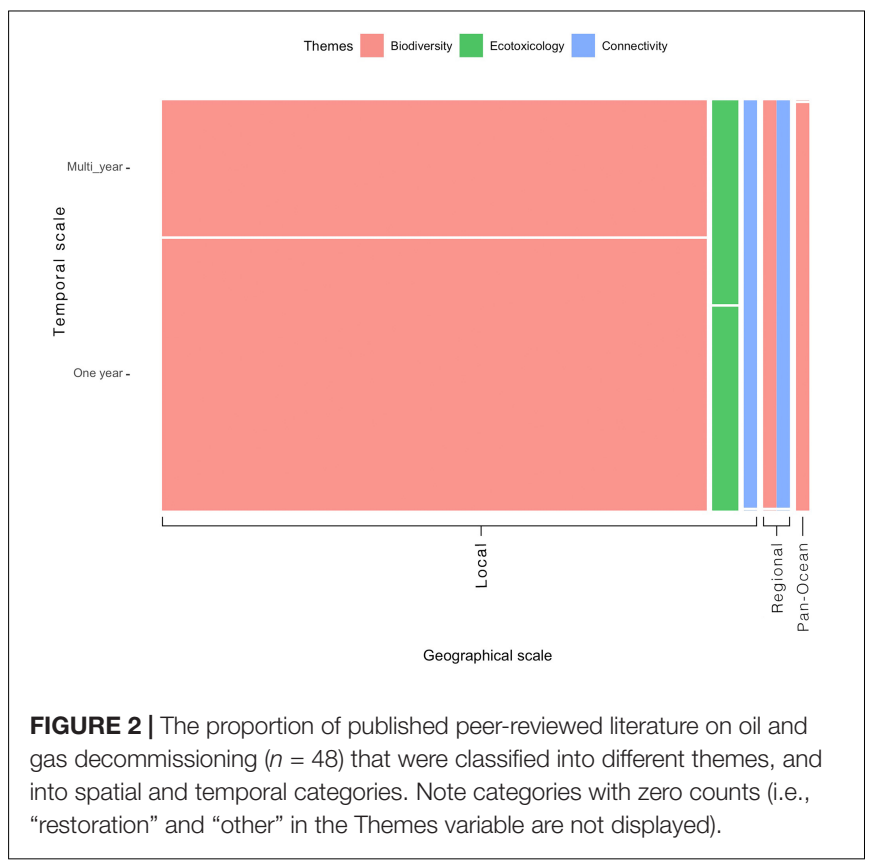

(derived from Shaw et al., 2018). The most frequent spatial scale was local $\left(\leq 100 \mathrm{~km}^{2}\right)$ and studies were often carried out once (i.e., $\leq 1$ year). Chi-square goodness-of-fit tests showed that the themes, and geographical spread were significantly different to an even distribution across categories (Themes: $p=1.13 \mathrm{E}-39$, Geographical scale: $p=2.24 \mathrm{E}-17, \alpha=0.05)$. Modeling studies were classified as multi-year, and this resulted in the observed frequencies between single and multi-year studies being not significantly different from each other $(p=0.249794, \alpha=0.05)$ (Supplementary Material).

We recognize that there are challenges involved with acquiring information about biological communities on/around O\&G structures. Carrying out field work at these locations is challenging (depth, safety training requirements, company buyin etc.). Analyzing ROV footage acquired for industry purposes is a first step but does not always guarantee the quality necessary for scientific studies (lack of replication), especially when quantifying marine sessile invertebrates [e.g., 6 months of viewing 5746.2 GB of industrial video at $7.5 \mathrm{~h}$ a day took 6 months and yielded only 428 usable photos (Schläppy pers. com)]. Archival footage is better suited to quantify fish biodiversity (Bond et al., 2018a; McLean et al., 2021). Although, research questions formulated by experts (Fowler et al., 2019) and other stakeholders (Shaw et al., 2018) encompass many themes that are important to make informed decisions (Figure 1), those themes, do not get reflected in the research that has been carried out to date, aside from biodiversity assessments.

When regulators need to make decisions and cannot wait for additional information, they have two options: (1) make decisions that are based on the available literature or (2) take into account other themes that have not been researched extensively and apply the precautionary principle. However, unlike in situations where it is clear what precautionary (in)action would be, it is more difficult to ascertain in the case of decommissioning because we do not know yet whether removing or retaining those structures is the more benign option for the environment. This is the reason why there is a pressing need for a wider variety of studies to be carried out. In a context of paucity of studies on alternative perspectives of value and risk of in situ decommissioning, it is understandable that nations with a "removal base-case" (e.g., United Kingdom, Australia, parts of the United States) are not yet prepared to consider in situ decommissioning as a valid option. Improving temporal and spatial scales of sampling could help, by generally increasing the gradients of environmental conditions and ecological responses observed (Hewitt et al., 2007). Collecting data at larger scales would increase the robustness of models predicting future ecological impacts in changing climate and environmental conditions. Of course, some degree of extrapolation will always be required, as novel climate and ecological responses will emerge in time (Williams et al., 2007; Moritz and Agudo, 2013).

To support decision-making that considers both the advantages of retaining and removing $O \& G$ subsea infrastructure in the context of a global increase in ocean sprawl (Firth et al., 2016), future efforts should address ecological questions beyond just biodiversity. This includes connectivity, ecotoxicology, restoration of historical assemblages and finding out whether 
collapsing or altered structures will harbor similar biodiversity. This would enhance the transparency, accountability and legitimacy of current decommissioning policies and regulations. Below, we highlight ecological knowledge gaps that should be addressed and considerations for assessing the advantages/disadvantages of in situ decommissioning, to reduce uncertainty in decision-making.

\section{CONSIDERATIONS FOR INTERPRETATION OF RESEARCH RESULTS AND KNOWLEDGE GAPS IN DECOMMISSIONING RESEARCH}

\section{Themes \\ Biodiversity}

This review revealed that most studies focused on biodiversity and more specifically on fish, with an emphasis on those of commercial value. Much less attention to date has been given to sessile invertebrates or how marine megafauna use and inhabit subsea structures (but see Robinson et al., 2013 and Russell et al., 2014). Although fish studies offer a valuable first step in our knowledge of assemblages on and around subsea structures, it would be highly valuable to broaden the scope and include other organisms, and thus be able to assess diverse trophic levels present on a given structure. The attraction of focusing on fish reflects the perceived social benefits that structures could bring to recreational and commercial fishers. In future, when discussing the value of subsea structures as a habitat for marine organisms, we suggest paying attention to the following points:

\section{The section of a subsea structure that remains in the water does matter}

We know that biodiversity on vertical subsea structures is largely dependent on depth (McLean et al., 2018; Thomson et al., 2018). On pipelines, biodiversity is higher at spans, and where structural complexity is enhanced due to sessile invertebrates (McLean et al., 2017). Therefore, not all parts of a subsea structure will have the same habitat value depending on where it is located. The value of biological assemblages on subsea structures should be formulated according to different scenarios: (a) retaining the whole structure; (b) retaining most of the structure except for the portion closest to the sea surface (e.g., platform jacket cut $50 \mathrm{~m}$ below the surface, or a pipeline cut 1-10 km from the shore); (c) removing most of the structure (cut 1-10 $\mathrm{m}$ above sediment). Thought should also be given to how the structural integrity of the structure will affect biodiversity in the future.

\section{The presence of pelagic fish around a subsea structure is not automatically positive}

Subsea structures may not be nurturing habitats for pelagic fish species even if these are attracted to them. Although artificial structures can attract pelagic fish, they could also become ecological traps (Schlaepfer et al., 2002) rather than ecological havens for two reasons: (1) fish at these locations will be easier to catch by fishers, and (2) pelagic fish species attracted to subsea structures may be physiologically disadvantaged by residing there. For instance, pelagic fish like Skipjack tuna Katsuwonus pelamis, and yellowfin tuna Thunnus albacares that are attracted to artificial structures i.e., fish aggregation devices (Fonteneau et al., 2000) for long periods of time have been shown to have emptier stomachs and be in poorer condition than conspecifics caught away from the structure (Hallier and Gaertner, 2008; Jaquemet et al., 2011). Future studies on the condition of organisms on and around subsea structures will enable us to test whether the structures offer an optimal habitat for pelagic and/or migratory species or whether their presence may only benefit fishers.

\section{Connectivity}

Research on the effect of offshore infrastructure on the metapopulations of different marine organisms already exists (Thorpe, 2012; Simons et al., 2016; van der Molen et al., 2018); however, with the increase of artificial offshore structures (e.g., offshore wind, tidal and wave energy devices), assessing the (cumulative) effect of those structures on marine communities is critical (Bailey et al., 2014; Goodale and Milman, 2016).

The value of biological assemblages on subsea structures is likely to be related to whether they are a source of larvae that spreads to natural communities and therefore will be a function of the extent of their connection with other structures and analogous natural assemblages. Sources and sinks of larvae could be modeled by including the main oceanic currents in a region, coupled with population genetic research. Even if a subsea O\&G structure produces larvae of "desirable" species, it might still not be of high ecological interest if the propagules are dispersed by ocean currents to unsuitable locations for their survival. Genetic information about connectivity could be obtained well before decommissioning is necessary, by comparing the genetic structure of organisms on structures to those in analogous natural habitats in the region. If the connectedness of the structures translates into the facilitated spread of invasive species, then connectivity is not conservation-enhancing. When considering the potential for any subsea structures to harbor and spread invasive species by functioning as stepping-stones (Rivas et al., 2010; De Mesel et al., 2015), larger spatial scales than those researched to date are also important. O\&G infrastructure has already initiated several species range extensions. Some of these species have gained pest status at their new location (Page et al., 2006; Sammarco et al., 2014; Tanasovici et al., 2020). Noting that current research on invasive species represents only $9 \%$ of biodiversity studies for in situ decommissioning research, a priority would be to investigate the propensity of invasive species to colonize subsea O\&G structures.

\section{Ecotoxicology}

Only two studies on decommissioning relate to the theme of ecotoxicology (i.e., Henry et al., 2017 and Lourenço et al., 2015). Ecotoxicology studies are necessary to uncover whether local pollution poses a health risk to organisms on and around subsea structures. This may have repercussions on whether polluted subsea structures constitute a nurturing environment that is conducive to them acting as a source or sink of larvae. We know that bioaccumulation occurs in some organisms such as 
mussels (Lourenço et al., 2015) but further ecotoxicological tests of contaminants, and organisms' tolerance are necessary. This is especially true for naturally occurring radioactive materials (NORMs) and plastics, to determine with increased certainty their effect on the growth, reproduction and survival of those organisms and the impact on humans through ingestion of fish caught at these locations. Knowledge gaps exist around species' tolerance to contaminants and which level of pollution exposure in water or sediment is deleterious. Laboratory experiments of sediment resuspension and the effect of NORMs would help to ascertain the rate of uptake by organisms and help predict their level across the food chain.

One of the arguments put forward in favor of in situ decommissioning of O\&G infrastructures is that the sediment plume and pollution associated with their removal will be deleterious to the biological assemblages on and around the subsea structures. There are three scenarios under which the sediment plume due to decommissioning could be more deleterious than the plume created while installing the infrastructure if: (1) the sediment suspension created by the decommissioning activity is higher than levels deemed acceptable during the development of the O\&G field (noting environmental standards may have changed in the intervening period); (2) new scientific evidence shows that lower sediment loads (than previously thought) are deleterious to nearby organisms; (3) the concentrations of pollutants released during the removal operations are above those currently leaching out from the sediments (Gray et al., 1990) and drill cuttings (Henry et al., 2017). Ecotoxicological studies are needed to fill those knowledge gaps and ascertain with more confidence the benefits of retaining or removing $O \& G$ structures.

\section{Structural Integrity}

No study addressed the theme of structural integrity, but stakeholders are concerned with this issue and have formulated questions on this subject (Shaw et al., 2018 and Figure 1). During operations, $O \& G$ companies fight to retain the structural integrity of infrastructure by carrying out maintenance and treatments, such a cathodic protection (to prevent oxidation of metals). Therefore, there is a poor understanding about how, when left in the water without care, these structures will lose their current structural integrity. Although this could be viewed as an engineering matter only, it is likely to have an effect on biodiversity and on the ecological significance of the assemblages present on and around the structure, especially if degradation of products are toxic or result in the loss of habitat. The current value given to those biological assemblages may differ in the future as a structure degrades.

\section{Restoration of Historical Assemblages}

On land, industries that create environmental disturbances, such as mining, are usually required to remediate the disturbed site when exploitation is finished. To our knowledge, this is not common practice for offshore O\&G operations. It is unclear whether restoration is possible, or whether these sites are in fact novel ecosystems whose value lies in a state, different to the historical and current state (van Elden et al., 2019). No studies were found on restoration of historical assemblages and stakeholders asked whether this is even possible, and with what success (Shaw et al., 2018). The first step to investigate this would be to carry out surveys at sites where subsea structures were removed. Access to those places is likely to be unrestricted, unlike access to active subsea structures. The biodiversity on subsea structures often appears to be much higher than adjacent communities (Bond et al., 2018b). However, many subsea structures with a hard surface cannot be meaningfully compared to the flat areas surrounding the structure that are often dominated by mobile sediments. Before in situ decommissioning can be considered a better environmental option than removal, the role of natural or restored historical assemblages should also be studied. For example, vast expanses of sediment with a mix of filter-feeders provide valuable ecosystem services, such as carbon sequestration.

\section{Spatial Scale}

The biodiversity of species found at a local scale was the focus of most published studies. How well the subsea structure is connected to analogous natural habitats (i.e., hard substratum, at the same depth) and the role of populations on structures in the context of the metapopulation are two aspects that will drive the value of biological assemblages on a subsea structure. Although local $\left(\leq 100 \mathrm{~km}^{2}\right)$ studies constitute a good start that makes the most of available industrial ROV footage, regional $\left(\leq 1000 \mathrm{~km}^{2}\right)$ studies are necessary when investigating connectivity.

\section{Status of an Organism's Metapopulation}

Subsea structures can influence larval recruitment, and therefore species conservation, by intercepting larvae that would normally recruit to natural habitats, thus depleting larval supply to natural habitats (no conservation gain). If the metapopulation is of a species that requires conservation, subsea structures could provide a habitat for recruitment and contribute recruits to natural habitats (conservation gain). If the metapopulation is healthy elsewhere, no additional gain is obtained from a species present on/around artificial structures especially if those function as ecological traps (see above). Considering these complexities, a precautionary approach would be to consider each species present on the subsea structures as ecologically neutral, until it is shown to be either deleterious or beneficial to its corresponding metapopulation, rather than implying that their presence is beneficial.

\section{Temporal Scale}

\section{Biological Assemblages Are Likely to Change Over Time}

Our review showed that 30 out of the 48 past studies collected data at one point in time $(\leq 1$ year), and that multi-year studies were less frequent (18/48, due to several multi-year modeling studies). Characterizing the biological assemblages found on and around O\&G subsea structures over less than 1 year is a good preliminary step. However, whether those assemblages are stable through time is uncertain. Studies should ideally consider temporal trends, using appropriate 
experimental designs to ensure multi-year comparisons that enhance the predictive power of the ecological value of those assemblages.

Assemblages may change seasonally, before/after natural events (e.g., heatwaves and storms). They may also change as a result of sloughing, may be influenced by the sewage and macerated food that is routinely discarded from crewed platforms (at levels allowed in permits) or by the heat produced during operations, which may favor or disfavor the settlement and survival of certain organisms. Given the difficulty of predicting future assemblages, their future ecological value is equally uncertain. To understand temporal dynamics of organisms on/around $\mathrm{O} \& \mathrm{G}$ infrastructure, surveys should be repeated over several years, well before in situ decommissioning becomes considered, using consistent methods to ensure that comparable data can be used for future predictions.

\section{CONCLUSION: A WAY FORWARD}

Ultimately, deciding on whether in situ decommissioning yields positive, negative, or neutral environmental outcomes requires a body of research on a range of themes. To achieve evidence-based management, science that spans multiple facets of ecology, and across larger spatial and temporal scales than the studies to date, will be required. The questions elicited from stakeholders and experts (Shaw et al., 2018; Fowler et al., 2019) and the studies published to date (Supplementary Material) mostly focus on the presence of biodiversity, especially of commercially important fish species. This is not surprising as this is one of the simplest question to address with existing industrial ROV footage, but this perspective unduly emphasizes the advantage of retaining subsea structures. So, while studies conducted to date constitute a valuable start, they partially reflect the availability of archival data, rather than what is required for a holistic approach to research on this topic.

Our identification of knowledge gaps suggests future research projects should also investigate the environmental effects of removing subsea infrastructures and cover ecologically meaningful spatial and temporal scales ${ }^{1}$. As decommissioning is becoming an increasingly global societal issue, partnerships between industry, government and philanthropists are necessary to effectively address the full suite of research questions. There is no doubt that considerable investment is required to adequately answer the full range of questions needed to inform a complete environmental assessment of in situ decommissioning. Prioritization of research questions could occur through a triage framework (Bottrill et al., 2008) or consultative processes (Wallace et al., 2016).

Ultimately, subsea O\&G structures are not the only artificial structures in the marine environment, and their ecological

${ }^{1}$ For example, projects funded by programmes such as the INfluence of manmade Structures In The Ecosystem (INSITE) in Europe and the National Decommissioning Research Initiative (NDRI) in Australia. role needs to be considered in synergy with other types of structures (e.g., shipwrecks, offshore wind turbines, wave and tide renewable energy infrastructure). How regulators decide to approach decommissioning of subsea O\&G structures is likely to pave the way for how the decommissioning of future marine renewable installations will be handled. Therefore, best practices must be adopted now, using evidence at the appropriate spatial and temporal scales, as this will contribute to equitable decisionmaking procedures, which is an investment towards present and future ocean health.

\section{DATA AVAILABILITY STATEMENT}

The original contributions presented in the study are included in the article/Supplementary Material, further inquiries can be directed to the corresponding author.

\section{AUTHOR CONTRIBUTIONS}

M-LS designed the study. M-LS, LR, and VC-A acquired and analyzed the data. M-LS, LR, VC-A, and KM interpreted the data, drafted the work, and revised it critically for important intellectual content, approved the final version to be published and agreed to be held accountable for all aspect of the work. All authors contributed to the article and approved the submitted version.

\section{FUNDING}

We thank the Australian Institute of Marine Science and the University of Western Australia (Ocean Institute) for financial support to M-LS through a competitively obtained research associate position and research funding.

\section{ACKNOWLEDGMENTS}

We thank the following persons "Don Poynton, Greg Oliver, Jenny Shaw, Ralph Talbot-Smith, Ronan Galaiduk, Tony Rouphael, and Jonathan D. Mitchell" for their comments and feedback on early drafts. The manuscript was improved by the comments of several industry contacts who actively work on decommissioning and their input was appreciated. Canaan Perry from the Barry J. Marshall Library at UWA provided invaluable assistance. We also thank the two reviewers whose comments improved the manuscript.

\section{SUPPLEMENTARY MATERIAL}

The Supplementary Material for this article can be found online at: https://www.frontiersin.org/articles/10.3389/fmars.2021. 642539/full\#supplementary-material 


\section{REFERENCES}

Bailey, H., Brookes, K. L., and Thompson, P. M. (2014). Assessing environmental impacts of offshore wind farms: lessons learned and recommendations for the future. Aquat. Biosyst. 10:8. doi: 10.1186/2046-9063-10-8

Bond, T., Langlois, T. J., Partridge, J. C., Birt, M. J., Malseed, B. E., Smith, L., et al. (2018a). Diel shifts and habitat associations of fish assemblages on a subsea pipeline. Fish. Res. 206, 220-234. doi: 10. 1016/j.fishres.2018.05.011

Bond, T., Partridge, J. C., Taylor, M. D., Langlois, T. J., Malseed, B. E., Smith, L. D., et al. (2018b). Fish associated with a subsea pipeline and adjacent seafloor of the north west shelf of western Australia. Mar. Environ. Res. 141, 53-65. doi: 10.1016/j.marenvres.2018.08.003

Bottrill, M. C., Joseph, L. N., Carwardine, J., Bode, M., Cook, C., Game, E. T., et al. (2008). Is conservation triage just smart decision making? Trends Ecol. Evol. 23, 649-654. doi: 10.1016/j.tree.2008.07.007

Cullinane, B., and Gourvenec, S. (2017). Decommissioning-the next Australian oil and gas boom? APPEA J. 57, 421-425. doi: 10.1071/aj16203

De Mesel, I., Kerckhof, F., Norro, A., Rumes, B., and Degraer, S. (2015). Succession and seasonal dynamics of the epifauna community on offshore wind farm foundations and their role as stepping stones for non-indigenous species. Hydrobiologia 756, 37-50. doi: 10.1007/s10750-014-2157-1

Fam, M. L., Konovessis, D., Ong, L. S., and Tan, H. K. (2018). A review of offshore decommissioning regulations in five countries-strengths and weaknesses. Ocean Eng. 160, 244-263. doi: 10.1016/j.oceaneng.2018.04.001

Firth, L. B., Knights, A. M., Bridger, D., Evans, A. J., Mieszkowska, N., Moore, P. J., et al. (2016). Ocean sprawl: challenges and opportunities for biodiversity management in a changing world. Oceanogr. Mar. Biol. Annu. Rev. 54, 193-269. doi: 10.1201/9781315368597

Fonteneau, A., Pallarés, P., and Pianet, R. (2000). "A worldwide review of purse seine fisheries on FADs," in Proceedings of the Conference Pêche Thonière et Dispositifs de Concentration de Poissons, 15-19 October, eds Y Le Gall, P Cayré and M Taquet (Martinique: IFREMER), 15-35.

Fowler, A. M., Jørgensen, A.-M., Coolen, J. W. P., Jones, D. O. B., Svendsen, J. C., Brabant, R., et al. (2019). The ecology of infrastructure decommissioning in the North Sea: what we need to know and how to achieve it. ICES J. Mar. Sci. 77, 1109-1126. doi: 10.1093/icesjms/fsz143

Fowler, A. M., Macreadie, P. I., Jones, D. O. B., and Booth, D. J. (2014). A multi-criteria decision approach to decommissioning of offshore oil and gas infrastructure. Ocean Coast. Manag. 87, 20-29. doi: 10.1016/j.ocecoaman.2013. 10.019

Fowler A. M., Jørgensen, A. M., Svendsen, J. C., Macreadie, P. I., Jones, D. O. B., Boon, A. R., et al. (2018). Environmental benefits of leaving offshore infrastructure in the ocean. Front. Ecol. Environ. 16, 571-578. doi: 10.1002/fee. 1827

Goodale, M. W., and Milman, A. (2016). Cumulative adverse effects of offshore wind energy development on wildlife. J. Environ. Plan. Manag. 59, 1-21. doi: 10.1080/09640568.2014.973483

Gray, J., Clarke, K., Warwick, R., and Hobbs, G. (1990). Detection of initial effects of pollution on marine benthos: an example from the Ekofisk and Eldfisk oilfields, North Sea. Mar. Ecol. Prog. Ser. 66, 285-299. doi: 10.3354/meps066285

Hallier, J. P., and Gaertner, D. (2008). Drifting fish aggregation devices could act as an ecological trap for tropical tuna species. Mar. Ecol. Prog. Ser. 353, 255-264. doi: $10.3354 /$ meps07180

Henry, L. A., Harries, D., Kingston, P., and Roberts, J. M. (2017). Historic scale and persistence of drill cuttings impacts on North Sea benthos. Mar. Environ. Res. 129, 219-228. doi: 10.1016/j.marenvres.2017.05.008

Hewitt, J. E., Thrush, S. F., Dayton, P. K., and Bonsdorff, E. (2007). The effect of spatial and temporal heterogeneity on the design and analysis of empirical studies of scale-dependent systems. Am. Nat. 169, 398-408. doi: 10.1086/51 0925

International Energy Agency (2019). Annual Average Decommissioning Need for Offshore Oil and Gas Assets by Region, 2000-2040. Available online at: https://www.iea.org/data-and-statistics/charts/annual-averagedecommissioning-need-for-offshore-oil-and-gas-assets-by-region-2000-2040 (accessed April 17, 2020).

Jaquemet, S., Potier, M., and Ménard, F. (2011). Do drifting and anchored Fish Aggregating Devices (FADs) similarly influence tuna feeding habits? A case study from the western Indian Ocean. Fish. Res. 107, 283-290. doi: 10.1016/j. fishres.2010.11.011

Kaiser, M. J., and Pulsipher, A. G. (2005). Rigs-to-reef programs in the Gulf of Mexico. Ocean Dev. Int. Law 36, 119-134. doi: 10.1080/00908320590943990

Krippendorff, K. (2004). Reliability in content analysis. Hum. Commun. Res. 30, 411-433.

Lourenço, A. R., Francisco de Oliveira, F., Haddad Nudi, A., Rebello Wagener, Â. de L, Guadalupe Meniconi, M. de F, and Francioni, E. (2015). PAH assessment in the main Brazilian offshore oil and gas production area using semi-permeable membrane devices (SPMD) and transplanted bivalves. Cont. Shelf Res. 101, 109-116. doi: 10.1016/j.csr.2015.04.010

McLean, D., Cure, K., Abdul Wahab, M. A., Galaiduk, R., Birt, M., Vaughan, B., et al. (2021). A comparison of marine communities along a subsea pipeline with those in surrounding seabed areas. Cont. Shelf Res. 219:104394. doi: 10.1016/j. csr.2021.104394

McLean, D. L., Partridge, J. C., Bond, T., Birt, M. J., Bornt, K. R., and Langlois, T. J. (2017). Using industry ROV videos to assess fish associations with subsea pipelines. Cont. Shelf Res. 141, 76-97. doi: 10.1016/j.csr.2017.05.006

McLean, D. L., Taylor, M. D., Partridge, J. C., Gibbons, B., Langlois, T. J., Malseed, B. E., et al. (2018). Fish and habitats on wellhead infrastructure on the north west shelf of Western Australia. Cont. Shelf Res. 164, 10-27. doi: 10.1016/j.csr. 2018.05.007

Moritz, C., and Agudo, R. (2013). The future of species under climate change: resilience or decline? Science 341, 504-508. doi: 10.1126/science.1237190

NOPSEMA (2020). Core Concepts. 1-25. Available online at: https://www. nopsema.gov.au/assets/Guidance-notes/A138249.pdf (accessed December 12, 2020).

OSPAR (1998). Sintra Statement (Vol. 45). Available online at: https://www.ospar. org/site/assets/files/36552/98_sintra_statement_english.pdf (accessed April 17, 2020).

Page, H. M., Dugan, J. E., Culver, C. S., and Hoesterey, J. C. (2006). Exotic invertebrate species on offshore oil platforms. Mar. Ecol. Prog. Ser. 325, 101107. doi: 10.3354/meps 325101

R Core Team (2021). A Language and Environment for Statistical Computing. R Foundation for Statistical Computing. Available online at: https://www.rproject.org/ (accessed February 3, 2021).

Rivas, G., Moore, A., Dholoo, E., and Mitchell, P. (2010). Alien invasive species: risk and management perspectives for the oil and gas industry. Society of Petroleum Engineers. Paper Presented at the SPE International Conference on Health, Safety and Environment in Oil and Gas Exploration and Production, Rio de Janeiro, 2482-2497.

Robinson, D. P., Jaidah, M. Y., Jabado, R. W., Lee-Brooks, K., Nour El-Din, N. M., Malki, A. A. A., et al. (2013). Whale sharks, rhincodon typus, aggregate around offshore platforms in Qatari waters of the Arabian Gulf to feed on fish spawn. PLoS One 8:e58255. doi: 10.1371/journal.pone.0058255

Russell, D. J. F., Brasseur, S. M. J. M., Thompson, D., Hastie, G. D., Janik, V. M., Aarts, G., et al. (2014). Marine Mammals Trace Anthropogenic Structures at Sea.in Current Biology, Vol. 24. Amsterdam: Elsevier Ltd, 638-639.

Sammarco, P. W., Porter, S. A., Sinclair, J., and Genazzio, M. (2014). Population expansion of a new invasive coral species, tubastraea micranthus, in the northern gulf of mexico. Mar. Ecol. Prog. Ser. 495, 161-173. doi: 10.3354/ meps 10576

Schlaepfer, M. A., Runge, M. C., and Sherman, P. W. (2002). Ecological and evolutionary traps. Trends Ecol. Evol. 17, 474-480. doi: 10.1016/S0169-5347(02) 02580-6

Shaw, J., Seares, P., and Newman, S. (2018). Decommissioning Offshore Infrastructure: A Review of Stakeholder Views and Science Priorities. Available online at: www.wamsi.org.au/decommissioning-offshoreinfrastructure-review-stakeholder-views-and-science-priorities (accessed June 19, 2020).

Simons, R. D., Page, H. M., Zaleski, S., Miller, R., Dugan, J. E., Schroeder, D. M., et al. (2016). The effects of anthropogenic structures on habitat connectivity and the potential spread of non-native invertebrate species in the offshore environment. PLoS One 11:e0152261. doi: 10.1371/journal.pone.0152261

Sommer, B., Fowler, A. M., Macreadie, P. I., Palandro, D. A., Aziz, A. C., and Booth, D. J. (2019). Decommissioning of offshore oil and gas structures-environmental opportunities and challenges. Sci. Total Environ. 658, 973-981. doi: 10.1016/j. scitotenv.2018.12.193 
Tanasovici, R. M., Kitahara, M. V., and Dias, G. M. (2020). Invasive coral Tubastraea spp. population growth in artificial habitats and its consequences to the diversity of benthic organisms. Mar. Biol. 167:119. doi: 10.1007/s00227020-03734-6

Techera, E. J., and Chandler, J. (2015). Offshore installations, decommissioning and artificial reefs: do current legal frameworks best serve the marine environment? Mar. Policy 59, 53-60. doi: 10.1016/j.marpol.2015.04.021

Thomson, P. G., Fowler, A. M., Davis, A. R., Pattiaratchi, C. B., and Booth, D. J. (2018). Some old movies become classics-a case study determining the scientific value of ROV inspection footage on a platform on Australia's North West Shelf. Front. Mar. Sci. 5:471. doi: 10.3389/fmars.2018.00471

Thorpe, S. A. (2012). On the biological connectivity of oil and gas platforms in the North Sea. Mar. Pollut. Bull. 64, 2770-2781. doi: 10.1016/j.marpolbul.2012.09. 011

van der Molen, J., García-García, L. M., Whomersley, P., Callaway, A., Posen, P. E., and Hyder, K. (2018). Connectivity of larval stages of sedentary marine communities between hard substrates and offshore structures in the North Sea. Sci. Rep. 8:14772. doi: 10.1038/s41598-018-32912-2

van Elden, S., Meeuwig, J. J., Hobbs, R. J., and Hemmi, J. M. (2019). Offshore oil and gas platforms as novel ecosystems: a global perspective. Front. Mar. Sci. 6:548. doi: $10.3389 /$ fmars. 2019.00548
Wallace, K. J., Wagner, C., and Smith, M. J. (2016). Eliciting human values for conservation planning and decisions: a global issue. J. Environ. Manag. 170, 160-168. doi: 10.1016/j.jenvman.2015.12.036

Wickham, H. (2016). ggplot2: Elegant Graphics for Data Analysis. New York, NY: Springer Verlag.

Williams, J. W., Jackson, S. T., and Kutzbach, J. E. (2007). Projected distributions of novel and disappearing climates by 2100 AD. Proc. Natl. Acad. Sci. U.S.A. 104, 5738-5742. doi: 10.1073/pnas.060629 2104

Conflict of Interest: The authors declare that the research was conducted in the absence of any commercial or financial relationships that could be construed as a potential conflict of interest.

Copyright (C) 2021 Schläppy, Robinson, Camilieri-Asch and Miller. This is an openaccess article distributed under the terms of the Creative Commons Attribution License (CC BY). The use, distribution or reproduction in other forums is permitted, provided the original author(s) and the copyright owner(s) are credited and that the original publication in this journal is cited, in accordance with accepted academic practice. No use, distribution or reproduction is permitted which does not comply with these terms. 